\title{
Humorous Dispositions Predicting Turnover among Early-Career Israeli Medical Clowns
}

\author{
Abira Reizer ( $\square$ abirar@ariel.ac.il ) \\ Ariel University https://orcid.org/0000-0002-0148-8613 \\ Meni Koslowsky \\ Ariel University Faculty of Social Sciences and Humanities \\ Rivki Antilevich-Steg \\ Ariel University Faculty of Social Sciences and Humanities
}

Research

Keywords: medical clowns, humor, turnover, job satisfaction, trauma

Posted Date: August 5th, 2020

DOI: https://doi.org/10.21203/rs.3.rs-51206/v1

License: (1) This work is licensed under a Creative Commons Attribution 4.0 International License. Read Full License 


\section{Abstract}

Background: In recent years, medical clowning research has received increasing interest. However, the clowns' dispositional factors associated with their turnover behavior have yet to be examined systematically.

Objectives: The current study examined whether individual differences in humor predict turnover behavior. This was accomplished by investigating the mediating role of the medical clowns' job satisfaction and the moderating role of previous traumatic experiences.

Method: Israeli medical clowns $(N=111)$ participated in a three-stage longitudinal study. Humorous dispositions were measured during the first week of medical clowning training, job satisfaction was measured two months later, and turnover behaviors were measured after six months.

Results: Findings revealed that higher humor appreciation was associated with actual turnover through the mediating role of job satisfaction, whereas humor creation directly increased turnover. In addition, previous traumatic experiences moderated the associations between humor appreciation and turnover.

Conclusion: Overall, our research findings support the notion that a humorous disposition can aid in predicting medical clowning turnover. As humor can be observed in numerous settings, in medicine as well as in other fields, we suggest implementing procedures to decrease the turnover rate of medical clowns.

\section{Background}

As a relatively new player in the health field, the medical clown profession was established to help ease the suffering, pain, and anxiety of hospital patients $[1,2]$. Medical clowns use humor in a very challenging health setting and must adjust and cope with a wide array of emotions and difficult situations [3]. To accomplish their goals, medical clowns are required to elicit smiles and laughter when interacting with patients, families, and medical staff $[3,1]$. Whereas recent studies have focused on the therapeutic benefits associated with the use of medical clowns [2], very few studies have investigated the clowns' personal characteristics and behavior [4, 5].

The current study aims to expand on previous work by focusing on adaptive humorous styles as specific dispositions in medical clowning. From a more traditional organizational perspective, the literature supports the potential benefits that employees can derive from humor and laughter. Specifically, a metaanalysis of the effects of adaptive humor styles showed that performance, job satisfaction, and employees' health outcomes were improved [6]. As only scant research has been reported regarding medical clowns, the present research focuses on the effects of medical clowns' humor styles on turnover and their potential moderators and mediators. Finally, since there is reason to believe that these unique personal qualities may have a greater influence on turnover early in the medical clowning experience, the 
current study followed medical clowns from the beginning of their training until the end of their internship period.

\section{Humor Styles}

In the current study, we focused on the adaptive humorous style. Thus, we adopted a two-dimensional conceptualization: humor appreciation (i.e., the ability to understand and enjoy messages containing humor) and humor creation (i.e., the ability to perceive relationships between people, objects, or ideas incongruously, as well as the ability to communicate this perception to others) [7]. Indeed, studies have shown that humor appreciation and humor creation comprise distinctive factors [8].

\section{Adaptive Humorous Dispositions and Turnover}

Turnover is one of the critical outcome measures in organizations, as substantial financial costs are associated with recruiting and training new employees [9]. Medical staff turnover has been identified as a global concern having potentially negative implications for patient treatment effectiveness and health outcomes [10]. As the job of a medical clown is accompanied by work challenges and difficulties [5], it seems critical to examine turnover among medical clowns and whether their use of humor contributes to decreasing the negative effects of turnover. Research in medical contexts indicates that the intention to remain in a job is a function of the fit between personal characteristics and various work environments [11]. Finally, whereas there is some evidence to support the association between humor and lower turnover levels among nurses in Korea [12], little is known of the impact of humor styles on medical clowns early in their careers. Thus, we posit the following hypotheses:

H 1a. Higher humor appreciation is associated with lower turnover rates among medical clowns early in their careers.

H1b: higher humor creation and humor appreciation are associated with lower turnover rates among medical clowns early in their careers.

\section{The Mediating Role of Job Satisfaction}

Job satisfaction is one of the most prevalent explanations for employee turnover [9], as individuals who do not like their jobs tend to leave them, as indicated by the recently published meta-analysis on both general turnover and voluntary turnover [13]. As noted, medical clowns use humor as their primary tool for enhancing the positive affect of patients, their families, and the medical staff [2]. Humor appreciation has been found to facilitate positive affect, which, in turn, may enable better mechanisms for confronting challenges at the workplace. [14], whereas humor creation has been found to enhance workers' general joy [6]. In addition, a previous meta-analysis indicated that job satisfaction mediates the association between personality dispositions and turnover behaviors [15]. Hence, we can suggest that adaptive humor would decrease medical clowning turnover under the mediation of increased job satisfaction. 
H2a: Job satisfaction mediates the association between humor appreciation and turnover among medical clowns.

$\mathrm{H} 2 \mathrm{~b}$ : Job satisfaction mediates the association between humor creation and turnover among medical clowns.

\section{The Moderating Role of Traumatic Stress}

Research has indicated that the incidence of childhood trauma (e.g., abuse, alcoholic parents, death of a parent or sibling) is frequently observed among mental health professionals and psychological counselors along with their positive and negative consequences. It has been suggested that the development of a general feeling of self-efficacy and a sense of control over life's adversities guide people to help others and thus aid in rectifying negative consequences from childhood [16].

In the current study, we will examine the effects of stressful events that may have preceded entry into the medical clowning volunteering experience to determine the extent to which their presence attenuates the association between humor and employee outcomes. The research literature supports a distinction between self-focused humor and humor focused on others, whereby the former would be relatively more effective as an aid in coping with traumatic events. Self-focused humor has been shown to be more effective under stressful experiences, as it can grant the individual an opportunity to reframe the negative stimulus [17]. Consistent with this argument, it was found that external stressors interacted with coping humor in decreasing burnout and PTSD symptoms among firefighters [17]. Moreover, the interaction between humor and stress in the Israeli army was found to significantly predict performance [18]. Hence, we argue here that previous trauma experiences interact with humor appreciation in predicting positive work outcomes. However, other-focused humor style, such as humor creation, may be more facilitative of an interpersonal and interactive environment and may be non-significant when a person is experiencing intrapersonal and prolonged stress [19]. As such, we posit the following hypothesis:

H3: The association between humor appreciation and turnover rates are stronger among medical clowns who have experienced traumatic life stressors compared to those who have not.

\section{Method}

\section{Sample and Procedure}

The current study included 111 participants in Israel $\left(72 \%\right.$ female; $\left.M_{\text {age }}=37.80, S D=14.20\right)$ who had just begun their training as medical clowns. At Time 1, the response rate was $92 \%$, and at Time $2,86 \%$, or 96 completed measures (seven left the study and eight refused to respond to the scales). All participants completed the questionnaires during the first two days of their training. Administered evaluations included personality traits--such as humor and Big Five factors--as well as previous experience with traumatic stressors. At the conclusion of the 10-week training course, the participants completed a training evaluation and satisfaction questionnaire based on their experiences in the hospital setting. In 
addition, the training organization provided us with information about the clown trainees that remained in the program as well as those who discontinued their training.

\section{Measures}

Humorous Disposition. The Sense of Humor Questionnaire SHQZ [7] comprises two 7- item subscales presented on a 5 -point Likert-type scale $(1=$ strongly disagree to $5=$ strongly agree $)$. One subscale measures humor appreciation (e.g., "I find many situations laughable"), yielding a Cronbach $a=.82$ in the current study. The second subscale, humor creation (e.g., "My friends expect me to make them laugh"), yielded a Cronbach a of .85. A principal component factor analysis resulted in the exclusion of Items 4 and 14 from the final scores, as they loaded in both factors. Consequently, the SHQZ yielded two scores, each derived from six items.

Job satisfaction. A 3-item questionnaire, adapted from Clary, Snyder, Ridge, et al. [20], was used to measure job satisfaction (e.g., "I am very satisfied with the responsibilities given to me as a medical clown"). Items were presented on a 5-point Likert-type scale, ranging from 1 (strongly disagree) to 5 (strongly agree), yielding a Cronbach a of .75 in the current study.

Turnover. Turnover data was collected at the conclusion of the clown trainees' internship, six months after the training began. Sixty-six participants $(60 \%)$ remained to the conclusion of the internship and began working in the hospital, whereas 45 (40\%) clown trainees discontinued their internship.

Traumatic stressor event. Participants were asked whether there was a meaningful and event in their life that influenced their decision to choose medical clowning ( $1=y e s, 0=n o)$. Approximately $33 \%$ of the participants responded affirmatively to this question, acknowledging an association between having experienced a life stressor and their choice of medical clowning. Using a well-known conceptualization of traumatic experiences [21], responses were coded by a research assistant to determine whether the reported event was indeed traumatic. Some of the responses included traumatic events that were experienced in the army, in marital life, or regarding a loss of close family members or friends. Previous research has suggested that a structured inquiry of traumatic history yields results similar to those derived from a trauma questionnaire [21]

Control variables. Two factors of the Big Five Inventory (BFI) [22] were measured in the current study. Openness to change was measured by $10 \mathrm{BFI}$ items presented on a 5-point Likert-type scale, ranging from 1 (strongly disagree) to 5 (strongly agree). A sample item included, "I see myself as someone who has an active imagination" ( $\mathrm{a}=.72$ ). Conscientiousness was measured by $9 \mathrm{BFI}$ items. A sample item included, "I see myself as someone who worries a lot" $(a=.77)$. Finally, we included years of education as a potential control variable.

\section{Results}

\section{Preliminary Data Analysis}


To examine whether humor appreciation and humor creation can be differentiated, a principal component factor analysis using varimax rotation was conducted. The two resulting factors, the first consisting of items associated with appreciation and the second with creation, explained $58 \%$ of the variance. Factor scores were then determined. The means, standard deviations, and correlations of the study variables are presented in Table 1. As expected, job satisfaction predicted turnover. However, no significant associations between humor styles and turnover behaviors were found. While mostly supportive of our expectations, bivariate correlations do not provide a complete account of unique relationships and, therefore, we proceeded to test mediation and indirect effects. as indirect effects can be observed even when direct correlations are non-significant [23].

TABLE 1.

Means, standard deviations, and zero-order bivariate correlations

\begin{tabular}{|llllllllll|}
\hline & Mean & SD & 1 & 2 & 3 & 4 & 5 & 6 & 7 \\
\hline 1. Humor-A & 5.06 & 1.32 & $(.83)$ & & & & & \\
\hline 2. Humor-C & 5.00 & 1.19 & .00 & $(.82)$ & & & & \\
\hline 3. Job satisfaction & 6.19 & .86 & $.33^{\star *}$ & .10 & $(.75)$ & & & \\
\hline 4. Openness to change & 4.17 & .51 & .12 & .08 & $.24^{*}$ & $(.72)$ & & \\
\hline 5. Conscientiousness & 3.85 & .69 & .14 & -.13 & .17 & $.27 * *$ & $(.77)$ & \\
\hline $\begin{array}{l}\text { 6. Education level } \\
\text { 7. Traumatic stressor-\# of } \\
\text { yes (\% of yes ) }\end{array}$ & 3.31 & 1.12 & -.01 & -.15 & .05 & .06 & .18 & - \\
\hline $\begin{array}{l}\text { 8. Turnover- \# of leavers } \\
\text { (\% of leavers) }\end{array}$ & $\begin{array}{l}43 \\
(40 \%)\end{array}$ & - & -.02 & .13 & .14 & .17 & $.22^{*}$ & -.11 & - \\
\hline
\end{tabular}

${ }^{\star} P<0.05,{ }^{\star *} P<0.01$; results in parentheses are reliabilities. Humor-A=Humor Appreciation; Humor$\mathrm{C}=$ Humor Creation. Means and standard deviations of humor scale represent the unweighted values of the items in each factor.

\section{The Mediating Role of Job Satisfaction}

To examine whether personality style explains unique variance in medical clowning persistence behavior, a logistic regression analysis was carried out (see Table 2). All measures were centered on their sample means to facilitate interpretation of the results and avoid multicollinearity. The first step of the regression included Consciousness, Openness to change, and educational level, which served as control variables. Humor appreciation and humor creation were included in the second step, followed by job satisfaction in 
the third step. The logistic regression analysis proved significant. The findings indicated that job satisfaction and humor creation significantly predicted turnover behavior.

TABLE 2. Logistic regression predicting turnover behaviors thru the mediating role of job satisfaction

\begin{tabular}{|c|c|c|c|c|c|c|c|c|c|}
\hline & \multicolumn{3}{|c|}{ Step 1} & \multicolumn{3}{|c|}{ Step 2} & \multicolumn{3}{|c|}{ Step 3} \\
\hline & B & $\mathrm{SE}$ & OR & $\mathrm{B}$ & $\mathrm{SE}$ & $\mathrm{OR}$ & $\mathrm{B}$ & SE & $\mathrm{OR}$ \\
\hline Openness to change & -.24 & .25 & .89 & -.15 & .26 & .86 & -.04 & .27 & .96 \\
\hline Conscientiousness & -.11 & .25 & .79 & -.22 & .26 & .80 & -.22 & .28 & .80 \\
\hline Education & -.45 & .24 & .64 & -.55 & .25 & $.58 *$ & -.65 & .28 & $.52 *$ \\
\hline Humor-Appreciation & & & & .10 & .26 & 1.11 & .42 & .30 & 1.51 \\
\hline Humor-Creation & & & & -.59 & .26 & $.56^{*}$ & $-.55^{*}$ & .26 & $.57 *$ \\
\hline Job satisfaction & & & & & & & -.105 & .36 & $.35 * *$ \\
\hline Change of $\chi^{2}$ & & 5.79 & & & $6.07 *$ & & & $10.04 *$ & \\
\hline Change of $d f$ & & 3 & & & 2 & & & 1 & \\
\hline-2 log likelihood & & 105.48 & & & 99.41 & & & 89.37 & \\
\hline Nagelkerke's $R$ & & .09 & & & $.18 *$ & & & $.32^{* *}$ & \\
\hline
\end{tabular}

$* P<0.05, * * P<0.01 . N=111 . \mathrm{SE}=$ standard error. $\mathrm{OR}=$ odds ratio.

To examine the indirect effects of humor on turnover through the mediating role of job satisfaction, bootstrapping mediation analysis was applied. This procedure examines whether an indirect path is significantly different from zero by producing a confidence interval $(\mathrm{Cl})$ for the indirect effect. The significance of the mediation paths was estimated by bias-corrected bootstrap analysis with 5,000 resamplings. Findings indicated that job satisfaction mediated the association between humor appreciation and turnover ( $\mathrm{b}=-.29,95 \% \mathrm{Cl}[-.73$ to -.03$])$, whereas no direct effect was found between humor appreciation and turnover after controlling for job satisfaction $(b=.42$, SE $=.30, P=.16)$, thus supporting $\mathrm{H} 2 \mathrm{a}$. The second bootstrap analysis revealed a significant direct path from humor creation to turnover $(b=-.55, S E=.26, P=0.03)$, whereas the indirect path via job satisfaction was non-significant (b $=-.09,95 \% \mathrm{Cl}[-.38, .09])$. Thus, these findings did not support $\mathrm{H} 2 \mathrm{~b}$.

\section{The Moderating Role of Previous Traumatic Events}

A binary regression was carried out in order to examine the moderating role of previous traumatic events. The control variables were entered in the first step of the regression. In the second step, humor appreciation, humor creation, and the trauma stressor were entered, followed by the interaction terms between humor and trauma in Step 3 (see Table 3). Findings supported Hypothesis 3, reflecting a 
moderating effect of traumatic stressors on the association between humor appreciation and turnover behavior $(b=1.08, P<0.001)$. The simple slope test was conducted to further examine the effect of humor creation under different conditions of traumatic stress. Results confirmed humor appreciation as a predictor of turnover, but only for individuals who had experienced previous trauma $(b=-.2 .04, P<0.01)$. Therefore, clowns who experienced traumatic events and used humor appreciation were less likely to leave the hospital than those who did not connect their vocational choice with trauma

TABLE 3. Logistic regression predicting turnover behaviors thru the moderating role of traumatic stressors

\begin{tabular}{|c|c|c|c|c|c|c|c|c|c|}
\hline & \multicolumn{3}{|c|}{ Step 1} & \multicolumn{3}{|c|}{ Step 2} & \multicolumn{3}{|c|}{ Step 3} \\
\hline & $\mathrm{B}$ & $\mathrm{SE}$ & $\mathrm{OR}$ & $\mathrm{B}$ & SE & $\mathrm{OR}$ & $\mathrm{B}$ & $\mathrm{SE}$ & OR \\
\hline Openness to changes & -.30 & .22 & .74 & -.25 & .23 & .78 & -.12 & .25 & .88 \\
\hline Conscientiousness & -.16 & .23 & .49 & -.13 & .24 & .88 & -.34 & .28 & .71 \\
\hline Education & -.44 & .22 & $.64^{*}$ & -.59 & .24 & $.56^{*}$ & -.66 & .27 & $.52^{*}$ \\
\hline Humor- Appreciation & & & & -.04 & .23 & .96 & -.08 & .32 & .92 \\
\hline Humor-Creation & & & & -.41 & .24 & $.66^{*}$ & -.65 & .29 & $.52^{*}$ \\
\hline Traumatic stressor & & & & -.33 & .24 & .72 & -.34 & .29 & .71 \\
\hline Humor-A*Traumatic stressor & & & & & & & -1.08 & .38 & $.34 * *$ \\
\hline Humor-C*Traumatic stressor & & & & & & & .45 & .28 & 1.56 \\
\hline Change of $\chi^{2}$ & \multicolumn{3}{|c|}{$7.72^{*}$} & \multicolumn{3}{|c|}{5.74} & \multicolumn{3}{|c|}{$17.98 * * *$} \\
\hline Change of $d f$ & \multicolumn{3}{|c|}{3} & \multicolumn{3}{|c|}{3} & \multicolumn{3}{|c|}{2} \\
\hline-2 log likelihood & \multicolumn{3}{|c|}{124.32} & \multicolumn{3}{|c|}{118.58} & \multicolumn{3}{|c|}{100.60} \\
\hline Nagelkerke's $R$ & \multicolumn{3}{|c|}{$.10^{*}$} & \multicolumn{3}{|c|}{$.18^{*}$} & \multicolumn{3}{|c|}{$.37 * * *$} \\
\hline
\end{tabular}

$* P<0.05, * * P<0.01, * * * P<0.001 . N=111 . \mathrm{SE}=$ standard error. $\mathrm{OR}=$ odds ratio.

\section{Discussion}

The present findings represent the first empirical test of turnover and job satisfaction among medical clowns as a function of humor creation and appreciation. More specifically, the current data indicated that humor appreciation predicted turnover through the mediating role of job satisfaction. It appears that the ability to enjoy and appreciate humor leads to an increase in positive mood, which may, in turn, serve as a predictor of job satisfaction [14]. In contrast, humor creation was not found to predict turnover through job satisfaction but rather impacts turnover directly. As humor creation is considered an interpersonal and social component of humor, it is expected to increase patients' positive feelings and reduce their hospitalized tension [2]. Moreover, humor creation may be less centered on the clowns' 
feelings of happiness. Pervious qualitative findings indicate how complicated and very specific is the role of the medical clown in the Israeli hospital environment. In their usual daily experiences, the medical clown works alone and, in some cases, in a non-supportive environment. Sometimes, their work is not particularly appreciated by the medical staff or the patients and their families who are often not receptive to their activities [5]. Therefore, their ability to appreciate humor as well as humor creativity serve as significant personal resources for medical clowns.

Regarding moderation, findings showed that among individuals who report previous traumatic experiences as a motive for becoming medical clowns, higher levels of humor appreciation were negatively associated with persistence ratings. The ability to look at life from a more humoristic perspective has been shown to enhance the self and places a different perspective on one's personal difficulties [24]. Previous literature on post-traumatic coping has indicated that the use of humor to cope with difficult life events is more likely to be accompanied by various types of growth experiences leading to positive outcomes [25]. These findings also support previous work suggesting that "general humor does have a positive relationship to individuals' functioning under stress" [18, p. 955].

This study had some methodological limitations that need to be acknowledged. The sample size in this study is relatively small, the participants comprising about a third of the total medical clown population in Israel notwithstanding. Second, the study examined medical clowning early in the clowns' career, during their training and internship periods, both of which are considered fundamental for shifting from one's own persona to the clown persona [3]. Future work would benefit from investigating medical clowning at different career stages.

The limitations notwithstanding, this study had several strengths. This work expands the evolving medical clowning studies by addressing the impact of personality dispositions on affective and behavioral outcomes. Our research design controls for common method variance and provides a clearer longitudinal explanation of the benefits of humor for those who use humor as a major component of their job duties and requirements. Further, the current findings suggest that medical clowning can be a useful area of exploration in turnover literature.

\section{Conclusion}

To sum up, previous research has indicated that medical clowns help in providing effective treatment by bringing out positive emotions in hospitalized patients [1]. Our research findings support the notion that a sense of humor aids in predicting personal outcomes for medical clowns. The findings clearly indicated that humor styles significantly contribute both to affective (job satisfaction) as well as behavioral (turnover) outcomes among medical clowns. Moreover, previous experiences of traumatic events play a significant role in moderating these associations. As research in this area of healthcare is in its early stages, we hope that future findings in the field would provide further evidence to make the hiring, training, and integration of medical clowns in a hospital setting more effective. 
Our study suggests several policy implications. Medical staff turnover has been identified as a global concern. Its ramifications extend to financial loss along with impairing patient treatment and health outcomes $[9,26]$. High turnover rates may affect the treatment efficiency due to the costs associated with recruitment and orientation of the newly hired clowns. And indeed, these since additional training and supervision practices, due to turnover, take time away from the treatment staff that could be better invested in patient treatment in the medical setting [10]. Based on our findings, we stress the importance of highlighting the individual psychological perspective of turnover. In particular, future policy regarding the selection process of medical clowns should define the candidate assessment to maximize the effects of training and minimize the harmful and costly effects of turnover. Training and supervision of medical clowns can be enriched with several interventions. For instance, encouraging medical clowns to use more self-enhancing humor is likely to improve their job satisfaction, lower their turnover, and ultimately, provide better patient care. Actions such as these would be particularly effective during their early stages in the profession Moreover, humor can be learned, trained, or otherwise leveraged for organizational advantage [28]. Finally, although medical clown interventions have been shown to mitigate the negative effects of hospitalization and have a positive impact on both patients and medical staff [1, 2, 4], it seems that we need a better understanding of clowns' personality in order to integrate them in the healthcare delivery system. In their typical work experience, the medical clown performs alone and, in some cases, in a non-supportive environment. At times, their work can be unappreciated by the medical staff or the patients and their families, who may not be receptive to their activities [5]. Implementing supportive policies can also provide a facilitative environment to the medical clowns in managing their challenging role.

\section{Declarations}

\section{Ethics approval and consent to participate.}

This study was carried out in accordance with the recommendations of three IRB members at the Ariel University. The protocol was approved by the IRB committee. All subjects gave written informed consent in accordance with the Declaration of Helsinki. We followed APA's ethical principles and code of conduct and ensured privacy, anonymity, and confidentiality with respect to study subjects' identity and results, and the analyses of the data in general. The nature of the data is non-invasive and participation in the study was voluntary (including the follow-up surveys) and we informed participants that we process their information as anonymized data. The written informed consent was obtained from the individual(s) and can be sent upon request

\section{Consent for Publication.}

Not applicable

\section{Availability of data and materials.}

The datasets generated for this study are available on request from the corresponding author 


\section{Competing interests.}

The authors declare that the research was conducted in the absence of any commercial or financial relationships that could be construed as a potential conflict of interest

\section{Funding.}

The author(s) received no financial support for the data collection process. However, Ariel University funds are available to support the publication fee.

\section{Authors' contributions.}

AR analyzed and interpreted the data and wrote the manuscript. MK contributed in writing the manuscript. RAS collected the data. All authors read and approved the final manuscript.

\section{Acknowledgements.}

Not applicable

\section{References}

1. Dionigi A, Canestrari C. Clowning in health care settings: The point of view of adults. Eur J Psychol 2016; 12: 473- 88.

2. Linge L. Joyful and serious intentions in the work of hospital clowns: a meta-analysis based on a 7year research project conducted in three parts. Int J Qual Stud Health Well-Being 2013; 8: 1-10.

3. Dionigi A, Ruch WF, Platt T. Components and determinants of the shift between own persona and the clown persona: a hierarchical analysis. Eur J Humour Res 2014; 1: 58-80.

4. Dionigi A. Personality of clown doctors. J Individ Differ 2016; 37: 49-55.

5. Nuttman-Shwartz O, Scheyer R, Tzioni H. Medical clowning:e adults deserve a dream. Soc Work Health Care 2010;49: 581-598.

6. Mesmer-Magnus J, Glew DJ, Viswesvaran C. A meta-analysis of positive humor in the workplace. $J$ Manag Psychol 2012; 27: 155-90.

7. Ziv A. The self-concept of adolescent humorists.J Adolesc 1981; 4: 187-97.

8. Kim TY. Lee DR, Wong NYS. Supervisor humor and employee outcomes: the role of social distance and affective trust in supervisor. J Bus Psycho/ 2016; 31:125-39.

9. Hom PW, Mitchell TR, Lee TW, Griffeth RW. Reviewing employee turnover: focusing on proximal withdrawal states and an expanded criterion. Psychol Bull 2012;138: 831-58.

10. Hassmiller SB, Cozine M. Addressing the nurse shortage to improve the quality of patient care. Health Aff 2006; 25:268-74.

11. Mullola S, Hakulinen C, Presseau J, et al. Personality traits and career choices among physicians in Finland: employment sector, clinical patient contact, specialty and change of specialty. BMC Med 
2018; 18: 52.

12. Kim J. Structural equation modeling for humor, job satisfaction, job stress and intention to turnover. Journal of Korean Academy of Nursing Administration 2013,19: 265-72.

13. Rubenstein AL, Eberly MB, Lee TW, Mitchell TR. Surveying the forest: a meta-analysis, moderator investigation, and future-oriented discussion of the antecedents of voluntary employee turnover. Pers Psychol 2018; 71:23-65.

14. Robert C, da Motta Veiga SD. Conversational humor and job satisfaction at work: exploring the role of humor production, appreciation, and positive affect. Humor 2017; doi:1515/humor-2017-0034

15. Zimmerman RD. Understanding the impact of personality traits on individuals' turnover decisions: a meta-analytic path model. Pers Psychol 2008; 61: 309-48.

16. Braunstein-Bercovitz H, Cohen E, Geller S, Benjamin BA. A career developmental perspective on the therapeutic alliance: implications for counseling. J Employ Couns 2014; 51: 50-58.

17. Sliter M, Kale A, Yuan Z. Is humor the best medicine? The buffering effect of coping humor on traumatic stressors in firefighters. J Organ Behav 2014; 35: 257-72.

18. Bizi S, Keinan G, Beit-Hallahmi B. (1988). Humor and coping with stress: A test under real-life conditions. Pers Individ Dif 1988; 9: 951-56.

19. Chen $\mathrm{GH}$, Martin RA. A comparison of humor styles, coping humor, and mental health between Chinese and Canadian university students. Humor 2007;20:215-34.

20. Clary EG, Snyder M, Ridge RD, et al. Understanding and assessing the motivations of volunteers: a functional approach. J Pers Soc Psychol 1998; 74:1516-30.

21. Kubany ES, Leisen MB, Kaplan AS, et al. Development and preliminary validation of a brief broadspectrum measure of trauma exposure: The Traumatic Life Events Questionnaire.Psychol Assess 2000; 12: 210-24.

22. John OP, Donahue EM, Kentle RL. The Big Five Inventory: Versions 4a and 54, Institute of Personality and Social Research. CA: University of California, 1991

23. Rucker DD, Preacher KJ, Tormala ZL, Petty RE. Mediation analysis in social psychology: current practices and new recommendations. Soc Pers Psychol Compass 2011; 5: 359-71.

24. Kuiper, NA. Humor and resiliency: towards a process model of coping and growth. EJOP 2012; 8: 475-91.

25. Scrignaro M, Barni S, Magrin ME. The combined contribution of social support and coping strategies in predicting post-traumatic growth: a longitudinal study on cancer patients. Psychooncology 2011; 20: 823-31.

26. Naburi H, Mujinja P, Kilewo C, Orsini N, Bärnighausen T, Manji, K, ... \& Ekström AM. Job satisfaction and turnover intentions among health care staff providing services for prevention of mother-to-child transmission of HIV in Dar es Salaam, Tanzania. Hum Resour Health 2017;15, 61- 67.

27. Hassmiller SB, Cozine M. Addressing the nurse shortage to improve the quality of patient care. Health Affairs 2006; 25: 268-274. 
28. Baisley MC, Grunberg NE. Bringing humor theory into practice: An interdisciplinary approach to online humor training. New Ideas in Psychology 2019; 55: 24-34. 